\title{
The Correlation Between the Big-Five Personality and Internet Addiction Among Early-Adult Individuals
}

\author{
Reinaldi Sugiarta ${ }^{1}$ Fransisca Iriani R. Dewi ${ }^{1 *}$ \\ ${ }^{I}$ Faculty of Psychology, Universitas Tarumanagara, Jakarta, Indonesia \\ "Corresponding author. Email: fransiscar@fpsi.untar.ac.id
}

\begin{abstract}
The internet, which makes it easier for humans to do activities, can have a negative impact. One of these negative effects is internet addiction. Internet addiction cases in Indonesia continue to increase along with the large number of internet usage. Internet addiction is uncontrolled use of the internet and causes annoying negative things. Several studies have shown that internet addiction is associated with the big five personality factor. It was found that the inconsistency of the research results on the big five personality dimensions . This study involved 69 individuals of early adulthood (aged 18 - 32 years ). Research measurement tools Internet Addiction Test (IAT) and Big Five Model - International Personality Item Pool - 25 (BFM-IPIP-25). Data analysis techniques for testing hypotheses using Pearson correlation. The findings showed a correlation significant between internet addiction premises dimensions agreeableness and emotional stability that is negative. Meanwhile, there is no correlation in the dimensions of extraversion, conscientiousness and intellect. The result is low emotional stability such as someone who has irritable behavior, stress and mood change have the value of a high internet addiction. Thus, low agreebleness, such as someone who behaves evil, cruelly and harms others, will have a high internet-addiction value.
\end{abstract}

Keywords: Internet Addiction, Big-Five Personality, Early-Adult, Extraversion, Agreeableness, Openness, Intellect, Emotional Stability, Neuroticism, Conscientiousness

\section{INTRODUCTION}

In the current era, people's life has depended a lot on the Internet. Technological developments entering the Industrial 4.0 era in Indonesia have an impact on the increasing dependence on the internet. The internet has evolved into something important for personal, professional and social life in most of the world's population [1]. The internet makes it easy for all human activities, from work matters such as controlling finances or stocks to daily affairs, namely communication. The existence of the internet is like being a life partner for humans themselves, thus increasing use of the internet in society.

The internet is one of the results of technological developments that greatly affect humans today. Entering the industrial era 4.0 in Indonesia, the internet has become a necessity. However, excessive and improper use of the internet can make the internet a negative impact. One of the negative impacts of using the internet is internet addiction.

The Indonesian Internet Service Providers Association ( APJII ) found the following: (a) There was an increase in internet users in Indonesia from 2017 to 2018 by 10.12 percent; (b) Java is peng g una largest internet in Indonesia; (c) Jakarta is peng g una largest internet in Java; (d) The biggest internet percentage at the age of 15-19 years, while the second position at the age of 20-24 years; (e) 93.4 percent of Internet user, using a smartphone to access the Internet; (f) Internet user using the Internet an average of more than eight hours a day; (g) 24.7 percent use the internet to communicate and 18.9 percent access social media [2] .

According to the data from a survey conducted by APJII in 2018, internet usage in Indonesia is increasing, and internet usage in Indonesia is concentrated in DKI Jakarta. In Indonesia, the internet is more widely used for communication and social media such as Whatsapp, Facebook, Twitter, Instagram and others. Applications from social media are accessed with a smartphone. The sixth rank of internet users, based on a survey from APJII, is dominated by the 15 until 44 year age group. The cause of this is at that age, people already know the internet and easily adapt the use of the internet for everyday activities. They belong to early adulthood .

The World Health Organization (WHO) suggested that increasing excessive internet use could become a new concern for public health [3] .The risk of using the internet that is increasingly widespread and increasing is the abuse of the internet, one example is internet addiction. The increase in internet addiction is also in line with the increase in smartphone use [4]. Spada stated that internet 
addiction can be defined as person's inability to control internet use causing psychological, school or office problems [5]. Ran Tao and colleagues defined excessive internet use as impulse control disorder [6] . Poor internet use can be associated with emotionally unstable, impulsive and aggressive [3]. According to Tikhonov and Bogoslovskii, internet addiction is an impulse disorder in the form of a very large individual desire to use the internet, difficulty managing time in using the internet, becoming irritated when disturbed while on the network and reduced social interaction in the real world [4]. One of the negative effects of internet addiction in Indonesia is the presence of a boy as young as 15 years old who suffer from disorders psychiatric due to the influence of the device. These symptoms may also occur in children aged 5-8 years [7]. It was found that 31.4 percent of teenagers in DKI Jakarta are addicted to the internet. This figure is the highest in Asia [8] .

Soh et al. in 2014 stated that poor parenting can be a major cause of internet addiction and was clarified by Oldmeadow, Quinn and Kowert in 2012 who stated that excessive internet use can be caused by dysfunction of closeness to parents, anxiety and avoidant parenting types [9]. Other studies suggest that personality can influence internet addiction [10]. This is supported by the research of Kayiş et al., Internet addiction is closely related to the Big Five Personality, which is one theory about personality [11] . Personality is a pattern of thought, feeling and behavior that distinguishes a person from others which will influence one's attitudes, beliefs, goals and needs [12]. Big five personality is a personality theory which consists of five dimensions, namely neurotics, extraversion, openness, agreeableness, and conscientiousnees [13].

Research conducted by Müller et al. stated that the significant dimensions associated with internet addiction are neuroticism, extraversion and conscientiousness[14]. In 2014 a study was conducted on internet addiction and personality with a sample of Italian students. Research result is the dimension of emotional stability and openness is not significantly correlated, but extraversion , agreeableness and conscientiousness obtain significant results [15]

Furthermore, the research conducted by Kayiş et al. about internet addiction and the Big Five Personality found that of the five dimensions only one dimension is related to internet addiction, namely neuroticism [11]. In a study conducted by Saini et al. stated that only extraversion and neuroticism had significant results with internet addiction [16] . Different results were obtained by Zhou et al. where all the dimensions of big five personality get significant results with internet addiction [17]

This research was conducted with various considerations. The development of the internet which aims to facilitate society but has a negative impact on society.

Inconsistencies in the five previous studies on the correlation between internet addiction and personality dimensions. An example is the conscientiousness dimension where three are significantly correlated [14][15] [17] and two are not significantly correlated [11][16]. In addition, there is a dimension of agreeableness where two statements are significantly correlated [15] [17] and three statements are not significantly correlated [11][14][16].

This study aims to examine the correlation between internet addiction and the big five personality dimensions. In addition, there is something that distinguishes this research from previous research, namely it was carried out with respondents domiciled in Indonesia, and this research was carried out when conditions were in a COVID-19 pandemic so that all activities were carried out via the internet.

\subsection{Related Work}

The use of the internet that can be accessed via a smartphone which is always carried by people makes using the internet easier. The internet, which makes it easier for everyone to do activities, can have a negative impact. One of these negative effects is internet addiction. Internet addiction is the use of the Internet can not be controlled and the resulting negative impact to user. Early adult age group is the largest internet user. Early adult age is able to take decisions on their own, so the time in internet usage is not restricted by others. At this age, a person has begun to be active in productivity and can use the internet smoothly.

Internet addiction can be influenced by various aspects, one of which is personality [11]. In personality, there are several theories, one of which is the big five personality which divides personality into five dimensions. The five dimensions are openness, neuroticism extraversion, conscientiousness, and agreeableness.

Internet addiction may or may not be related significantly to the dimension of the big five personality. In extraversion may have a correlation with internet addiction as in dealing with other people can use applications that connect using the internet. At openness can have a correlation with internet addiction because of knowledge and new ideas can be viewed and searched through an abundant source of internet. Agreeableness can be related to internet addiction because if someone has low agreebleness, that person will not be able to follow their surroundings so they will escape to the internet. Conscientiousness can relate to the internet because some features on the internet make it easier to do things and be more organized. On neuroticism may be associated because the Internet is one source of entertainment to relieve stress or mood is not good.

\subsection{Our Contribution}

The theoretical benefit of this research is to become additional knowledge pre-existing knowledge, information, theory and data, and to contribute knowledge about Big Five Personality, internet addiction in early adult individuals. The practical benefits of this research are to add insight and experience to researchers and early 
adults social media users in discussing big five personality of early adults individuals in internet addiction.

\subsection{Paper Structure}

This paper is divided into five sections. Section 1 and 2 consist of research background and the goal of this study. In Section 3 (Methods), participants of the study, measurement used, data analysis plan is discussed. Section 4 presents the analysis result and findings of this study, and its implication. Lastly, Section 5 presents the conclusion of this paper as well as direction for future research.

\section{BACKGROUND}

\subsection{Internet Addiction}

Internet addiction is the behavior of a person who loses control of internet use and has a negative impact on psychological, social, education / work [18][4][5][17]. Internet addiction can also be interpreted as problematic internet use, playing games excessively and using the internet excessively [19]. The idea of internet addiction was initiated by Young in 1998 based on the criteria of pathological gambling [5].

Internet addiction can cause negative impacts in terms of physical health, family, academic, work and psychological problems. Physical problems can occur because someone who is addicted to the internet causes a heavy lack of food but eats snacks, lack of sleep and lack of movement. The results of the foregoing on physique are obesity, weak vision and backache. Family problems occur because of the absence of a relationship with the family due to being too busy with the internet, having an affair or having other relationships with people on the internet, and hiding bills or things purchased on the internet. In academics and work it occurs because a person's performance is drastically reduced due to too long using the internet [1].

There are therapies that can be done for internet addiction such as cognitive behavior therapy (CBT), family therapy and drug therapy. CBT teaches patients to control their thoughts and feelings in order to trigger the impulse to leave the virtual world. Family therapy can be used for adolescents, by improving relationships and communication with families so that these teens can be separated from the internet.

\subsection{Big-Five Personality}

Big-five personality is a personality theory based on traits. Big-five personality is based on Eysenck's personality theory and was developed by McCrae and Costa [13]. The personality approach to the big-five personality is based on traits [20]. King [21] states that the big-five personality consists of five traits that can be transformed into OCEAN, namely openness, conscientiousness, extraversion, aggreeableness and neuroticism.

Big-five personality in the openness factor is related to the nature of a person to accept new ideas, conscientiousness is related to one's obedience to follow applicable rules or discipline, extraversion is related to one's comfort to socialize and relate to other people, agreeableness is related to whether one's actions are good or cruel and neuroticism is related to how negative one's emotions are [13].

\subsection{Early Adulthood}

Early adulthood also becalled young adulthood starting at the age of 18 years to mid $40 \mathrm{~s}$ years [22]. In early adulthood, there are several behaviors that affect the health of a person in early adulthood such as diet and nutrition; obesity; eating disorders; physical activity; stress; sleep patterns; smoke; and drinking alcohol. People in early adulthood are found to lack of healthy diet, lack of physical activity and irregular sleep patterns that lead to lack of sleep [22]. For early adulthood, mental health problems sometimes arise such as alcohol dependence, drug use and depression [22]. Before entering early adulthood, there is a stage where the transition from adolescence to early adulthood is the emerging adulthood stage. According to Arnet in 2000, at the emerging adulthood stage, a person cannot be said to be a adolescent anymore but is still looking for a role as an adult [22].

According to Arnet [22] there are three criteria to be called an adult, namely a) taking responsibility yourself; b) make their own decisions; and c) be financially independent. Nowadays, the signs that a person has entered adulthood are entering college, working, leaving home, getting married, and having children.

\section{METHOD}

Subjects in this study have individual characteristics aged 18 to 40 years. Subjects are not limited by gender, religion, ethnicity and race. The population of this research is community members aged 18 to 40 years who are active in using the internet in their daily lives. The results of the data collection process, finally obtained 69 subjects. Subjects will be financed based on two criteria, namely age and work status. Based on these criteria, a different test will be carried out with One Way ANOVA whether differences in age or work status will result in significant differences in the IAT score. In table 1, it can be seen that the test for the total difference in IAT scores by age, the result obtained is that there is no significant difference between the three age groups in the IAT score with $\mathrm{F}$ $(2.66)=0.857, \mathrm{p}=0.429(>0.05)$. 
Table 1. One-Way ANOVA Difference Test Total IAT Score Based on Age

\begin{tabular}{ccccccccc}
\hline & N & Mean & Std. Deviation Std. Error & $\begin{array}{c}\mathbf{9 5 \%} \text { Confidence Interval for } \\
\text { Mean }\end{array}$ & Minimum Maximum \\
\cline { 5 - 7 } & & & & & Lower Bound & Upper Bound & \\
\hline $18-20$ & 15 & 46.3333 & 11.05613 & 2.85468 & 40,2107 & 52.4560 & 21.00 & 66.00 \\
$21-25$ & 50 & 47,4000 & 12.89676 & 1,82388 & 43.7348 & 51.0652 & 31.00 & 82.00 \\
$26-30$ & 4 & 39,0000 & 9.76388 & 4.88194 & 23.4635 & 54,5365 & 31.00 & 53.00 \\
\hline Total & 69 & 46.6812 & 12.37347 & 1.48959 & 43,7087 & 49.6536 & 21.00 & 82.00 \\
\hline
\end{tabular}

Table 2 shows the results of different tests based on work work status and $\mathrm{F}(1.67)=2.271, \mathrm{p}=0.137(>0.05)$ status, it was found that there was no significant difference between

Table 2. One-Way ANOVA Difference Test Total IAT Score Based on Work Status

\begin{tabular}{|c|c|c|c|c|c|c|c|c|}
\hline & \multirow[t]{2}{*}{$\mathbf{N}$} & \multirow[t]{2}{*}{ Mean } & \multirow[t]{2}{*}{ SD } & \multirow[t]{2}{*}{ SE } & \multicolumn{2}{|c|}{$\begin{array}{l}\text { 95\% Confidence Interval } \\
\text { for Mean }\end{array}$} & \multirow[t]{2}{*}{ Min } & \multirow[t]{2}{*}{ Max } \\
\hline & & & & & $\begin{array}{l}\text { Lower } \\
\text { Bound }\end{array}$ & $\begin{array}{l}\text { Upper } \\
\text { Bound }\end{array}$ & & \\
\hline Doesn't work & 49 & 48.1020 & 13,56811 & 1,93830 & 44,2048 & 51.9993 & 21.00 & 82.00 \\
\hline Work & 20 & 43,2000 & 8,05638 & 1.80146 & 39.4295 & 46,9705 & 32.00 & 62.00 \\
\hline Total & 69 & 46.6812 & 12.37347 & 1.48959 & 43,7087 & 49.6536 & 21.00 & 82.00 \\
\hline
\end{tabular}

The type of research taken in this study is quantitative correlational. Correlational research aims to find the relationship and the level of the relationship between two or more variables without affecting these variables. Quantitative research is research that uses numbers as data to be processed to systematically analyze phenomena or events. This study uses two variables, namely big five personality as the independent variable and internet addiction as the dependent variable.

The measuring instrument used to measure the big five personality is the International Personality Item Pool - Big Five Factor Marker-25 or shortened to IPIP-BFM25 . IPIP-BFM-25 consists of 25 statement items that measure the five factors of the big five personality. In addition, each item is measured using a Likert scale which has five choices from strongly disagree to strongly agree [23]. This measuring instrument is tested for reliability first by taking the tryout data using 37 respondents. The reliability of the data results was tested by using the Cronbach-alpha test on each dimension. Item five is eliminated to improve the reliability value of the intellectual dimension.

The IPIP-BFM-25 test kit is a test kit made based on the IPIP-BFM-50 test kit. The reason for using this test tool to measure the big five personality is because it has advantages over personality tests that have a lot of statement/ items, namely it does not take a lot of time to do it, makes administration easier, uses cost effectively, and avoids boredom from respondents [23].

In IPIP-BFM-25, the neuroticism dimension is replaced by the emotional stability dimension, between the two dimensions has a negative correlation [23]. Meanwhile, the openness dimension is replaced by the intellectual dimension.

The intellect dimension arises because there are several arguments that the openness dimension exists as an artifact of a correlated matrix, not as an actual. Researchers began to argue that the questionnaire measuring openness lexically measures intellect and desire for knowledge. In several subsequent studies, it was found that openness and intellect are independent but related dimensions [16]. The measuring instrument used to measure internet addiction is the internet addiction test (IAT). The IAT consists of 20 questions filled with six choices with levels ranging from never represented by the number 0 to always represented by the number five. IAT is tested for reliability by taking 37 respondents for the tryout . The reliability test used was the Cronbach-alpha test. P there is a corrected item-total correlation, item 4 gets a number below 0.2, namely 0.152 . This causes item 4 to be eliminated and the reliability calculation is carried out again. The final result obtained in the reliability test is 0.913 .

\section{FINDING AND DISCUSSION}

The internet addiction variable is measured using a test tool in the form of the IAT developed by Young in 1998). Testing on 69 subjects who tested the IAT score difference with age and work status, there was no significant difference between age and work status differences in the IAT score. 
The big five personality variable is measured using the IPIP-BFM-25. IPIP-BFM-25 measures five dimensions, namely extraversion, conscientiousness, agreeableness, emotional stability, and intellect. On the extraversion dimension, the mean data is 14.75 with a standard deviation of 4.444. The minimum value obtained is 6 with a maximum value of 24 . This dimension gets a mean value of 18.22 , with a standard deviation of 3.678 . The minimum and maximum values obtained were 12 and 25 . In the agreeableness dimension, the mean value was 20,64 with a standard deviation of 3.706. Minimum value on this dimension is 6 and a maximum of 25. Emotional Stability has a mean by 12.03 with a standard deviation of 3.417. Value obtained minimum is 6 , with a maximum of 20. Dimensi intellect mend apatkan mean value amounting to $14: 36$, and value a standard deviation of 2.880 . The minimum data obtained is 8 and the maximum is 20 . The big five variable will be described in each of its dimensions. At dimension of extraversion obtained Kolmogorov-Smirnov $\mathrm{Z}=.0705$ and $\mathrm{p}=.0703$ (> $0.05)$. Then on the agreeableness dimension, it was obtained Kolmogorov Smirnov Z $=1.195$ and $p=0.115$ (> 0.05). Furthermore, the dimension of conscientiousness is Kolmogorov Smirnov $\mathrm{Z}=1.001, \mathrm{p}=0.269$ (> 0.05).

Emotional stability gained by Kolmogorov-Smirnov $\mathrm{Z}=$ 0.932, $\mathrm{p}=0.351$. Lastly, intellect with Kolomogorov Smirnov $\mathrm{Z}=1.210, \mathrm{p}=0.107$.

The description of the results of the previous normality test can conclude the conclusion regarding the normality of the data obtained. In the internet addiction variable, data is found to be normally distributed. The big five variable gets data results that are normally distributed in its five dimensions.

After the assumption test has been carried out, it can be continued to the next stage, which is to test whether there is a correlation between the variables. Pearson technique is used to analyze the correlation. Dimensions using correlation Pearson is the fifth dimension of the Big Five Personality. The results of correlation testing using Pearson showed that the correlation between internet addiction and extraversion was $r=-0.046, \quad p=0.705$ (> 0.05). On agreeableness, get $\mathrm{r}=-0.290, \mathrm{p}=0.016$ (< $0.05)$. Then conscientiousness gets $r=-0.095, p=0.437$. Emotional stability dimension gets $\mathrm{r}=-0,354, \mathrm{p}=0.003$. Finally, the intellect dimension gets $r=-0.095, p=0.440$. When viewed from the results of the correlation test above, several results can be seen. The results obtained are that there are 2 dimensions that are significantly correlated with internet addiction and 3 dimensions that are not significantly correlated with internet addiction. Two dimensions that correlate significantly with internet addiction are agreeableness and emotional stability. The three dimensions that do not significantly correlate with, internet addiction are extraversion conscientiousness and intellect.

In agreeableness correlated significantly and negatively on internet addiction because, if the lower agreeableness, the higher its Internet addiction. This can be caused if someone cannot integrate with their environment like someone who has low agreebleness will use the internet more often, this is in accordance with the statement by Saini in 2016 [16]. Someone who has low agreeableness tends to be cruel, selfish and make people around him uncomfortable. This makes the individual isolated or doesn't have many friends, so that the individual will have plenty of time to use the internet and the internet will not stay away even if the individual is cruel or selfish.

Emotional stability has a significant but negative relationship to internet addiction. This is because the lower emotional stability which leads to neuroticism, the individual will tend to be more easily stressed or have a bad mood. During times of stress or a bad mood, these individuals will tend to cope with it by using the internet until they feel stressed or the mood begins to improve [11, $14,16,17]$.

When the individual is in a state of stress or a bad mood, the individual will look for ways to relieve stress or make up for the bad mood. Internet provides entertainment to relieve stress, such as videos, music, and games [11]. However, this will not eliminate the source of the stress, so that the individual will continue to use the internet as a repetition until the individual resolves the source of stress or makes the mood uncomfortable.

The limitation in this study is the number of respondents who are less numerous and less diverse. In addition, the researchers reduced each one item of the statement or question from the test kit because they misinterpreted the results of the tryouts with a small number of tryout respondents.

\section{CONCLUSIONS}

Based on the results of the data obtained and processed, several conclusions can be concluded. First, there is no significant correlation between internet addiction and the three big five dimensions, namely extraversion, intellect and concientiousness and intellect. Second,there is a significant correlation between internet addiction and the two big five dimensions, namely agreeableness and neuroticism (emotional stability) with a negative correlation.

The theoretical benefit in this study is to contribute information about internet addiction and big personality. The study has several limitations that could be improved to provide better data. Expandable number of respondents, expandable domicile can provide a better picture of internet addiction and big five personality. In addition, research can be carried out with a mix method in order to obtain more in-depth data than using only quantitative methods.

In research, the dimensions of emotional stability or neuroticism have a significant relationship. Based on this, one way to reduce the spread of internet addiction is to maintain mental health, or stress from individuals. Several studies have revealed that the internet is a coping medium when stressed. Keeping you from stress can be quite effective in avoiding internet addiction. There are other things that can be done for coping with stress besides 
using the internet, such as exercising, gardening and other things that don't use the internet.

\section{REFERENCES}

[1] Bisen, SS, \& Deshpande, YM (2018). Understanding internet addiction: a comprehensive review. Mental Health Review Journal, 23 (3), 165184. https://doi.org/10.1108/MHRJ-07-2017-0023

[2] APJII. (2018). Penetration \& Behavior Profiles of Indonesian Internet Users. Apjii. www.apjii.or.id

[3] Guglielmucci, F., \& Granieri, A. (2017). Personality profiles and problematic Internet use: a study with a sample of Italian adolescents. February

[4] Ryding, F.C, \& Kaye, L.K (2018). "Internet Addiction": a Conceptual Minefield. International Journal of Mental Health and Addiction, 16(1), 225232. https://doi.org/10.1007/s11469-017-9811-6

[5] Spada, MM (2014). An overview of problematic Internet use. Addictive Behaviors, 39(1)3-6. https://doi. org/10.1016/j.addbeh.2013.09.007

[6] Kumar, N., Kumar, A., Mahto, SK, Kandpal, M., Deshpande, SN, \& Tanwar, P. (2019). Prevalence of excessive internet use and its correlation with associated psychopathology in 11th and 12th grade students. General Psychiatry, 3(2).1-8. https://doi.org/ 10.1136/gpsych-2018-100001

[7] Mental Hospital in West Java Starts Flooded with Child Cellphone Addict Patients - Rumah Baca2. (2019). Read House 2. https://rumah-baca2.blogspot. com/2019/10/rumah-sakit-jiwa-di-jawa-barat-mulai. $\mathrm{html} ? \mathrm{~m}=1$

[8] Sulaiman, MR, \& Efendi, DA (2019). Highest in Asia, 31 Percent of Teenagers in Jakarta Addicted to the Internet. Suara.com. https://www.suara.com/health/ 2019/11/20/060500/tertinggi-di-asia-31-persen-remajadi-jakarta-kec]-internet

[9] Adams, M. (2017). Internet Addiction: Prevalence, Risk Factors And Health Effects. Nova Science Publishers, Inc.

[10] Floros, G., \& Siomos, K. (2014). Excessive Internet Use and Personality Traits. Curr Behav Neurosci Rep 1, 19-26. https://doi.org/10.1007/s40473014-0006-1
[11] Kayiş, AR, Satici, SA, Yilmaz, MF, Şimşek, D., Ceyhan, E., \& Bakioğlu, F. (2016). Big five-personality trait and internet addiction: A meta-analytic review. Computers in Human Behavior, 63, 3540. https://doi.org/10.1016/j.chb.2016.05.012

[12] Kozan, H. İ. Ö., Baloğlu, M., Kesici, Ş., \& Arpac1, İ. (2019). The Role of Personality and Psychological Needs on the Problematic Internet Use and Problematic Social Media Use. 6 (2). https://doi.org/10.15805/ addicta.2019.6.2.0029

[13] Feist, J., \& Feist, GJ (2009). Theories of personality. McGraw Hill Higher Education.

[14] Müller, KW, Koch, A., Dickenhorst, U., Beutel, ME, Duven, E., \& Wölfling, K. (2013). Addressing the question of disorder-specific risk factors of internet addiction: A comparison of personality traits in patients with addictive behaviors and comorbid internet addiction. BioMed Research International. https://doi. org/10.1155/2013/546342

[15] Servidio, R. (2014). Exploring the effects of demographic factors, Internet usage and personality traits on Internet addiction in a sample of Italian university students. Computers in Human Behavior, 35, 85-92. https://doi.org/10.1016/j.chb.2014.02.024

[16] Saini, V., Baniya, G., Verma, K., Soni, A., \& Kesharwani, S. (2016). A study on relationship of internet addictive behavior with personality traits among medical students. Journal of Mental Health and Human Behavior, 21 (2), 108-111. https://doi.org/10. 4103/0971-8990.193429

[17] Zhou, Y., Li, D., Li, X., Wang, Y., \& Zhao, L. (2017). Addictive Behaviors Big five personality and adolescent Internet addiction: The mediating role of coping style. Addictive Behaviors, 64, 42-48. https:// doi.org/10.1016/j.addbeh.2016.08.009

[18] Bozoglan, B. (2018). Psychological, Social, and Cultural Aspects of Internet Addiction. In B. Bozoglan (Ed.), Internet and Technology Addiction. IGI Global. https://doi.org/10.4018/978-1-5225-8900-6.Ch 002

[19] Neging, P., Musa, R., \& Wahab, RA (2015). The Determinants and Outcomes of Pathological Internet use (PIU) among Urban Millennial Teens: A Theoretical Framework. February 2013.

[20] Putri, LN (2018). The Big Five Personality Of Personality And The Use Of Social Media In Teens. Muhammadiyah University of Malang. 
[21] King, LA (2016). The science of psychology: An appreciative view. McGraw Hill Higher Education

[22] Papalia, DE, Feldman, RD, \& Martorell, G. (2015). Experience human development (13th Ed.). McGraw Hill Higher Education.

[23] Akhtar, H., \& Azwar, S. (2018). Development and Validation of a Short Scale for Measuring Big Five Personality Traits: the Ipip-Bfm-25 Indonesia. Journal of Innovation in Psychology, Education and Didactics, 2 (2), 167-174. http://ipip.ori.org/index.htm 